\title{
VARIABILITY OF EMISSION RATE DEFINITION IN REGULATORY ODOUR DISPERSION MODELLING FROM CIVIL WASTEWATER TREATMENT PLANTS
}

\author{
MARCO RAVINA, SALVATORE BRUZZESE, DEBORAH PANEPINTO \& MARIACHIARA ZANETTI \\ Department of Environment, Land and Infrastructure Engineering, Politecnico di Torino Italy
}

\begin{abstract}
The analysis of odour impacts in civil wastewater treatment plants (WWTPs) is a challenging task. Odour regulations still present a lack of standardization, that bring inherent levels of uncertainty to the analysis procedure. Dispersion models can provide support towards the characterization and reduction of odour nuisances. The application of dispersion models requires an adapt setting and a detailed characterization of the emission sources, in terms of emission rate. In this study odour dispersion of a large WWTP in northern Italy was considered. Simulations were carried out with the CALPUFF model. The study focused on the selection of the open field correction method for wind velocity used in the calculation of odour emission rates (OERs). Three different relationships were considered: the power law, the logarithmic law and the Deaves-Harris (D-H) law. The area underlying the $1 \mathrm{OU} / \mathrm{m}^{3}, 3 \mathrm{OU} / \mathrm{m}^{3}$, and $5 \mathrm{OU} / \mathrm{m}^{3}$ concentration isopleths was considered as indicator. The results showed that OERs and impact area varied depending on the selected method. Taking the power law as the reference, the average variability of the impact area was between $-33 \%$ and $-48 \%$ if the logarithmic law was applied, and $-83 \%$ and $-94 \%$ if the D-H law was applied. The present study provides knowledge towards a better alignment of the concept of the odour impact criteria.

Keywords: odour impact assessment, odour emission rate, dispersion modelling, wastewater treatment, odour impact criteria.
\end{abstract}

\section{INTRODUCTION}

Odour impact assessment is a complex and debated topic in the scientific research community. Wastewater treatment plants (WWTPs) are known sources of odours, because these facilities are often located in urban and territorial contexts. An olfactory impact evaluation strategy is required for WWTPs, to limit odour impacts in the surrounding area, allowing the correct process management. Odour impact assessment presents multiple aspects of complexity. It is recommended that an integrated multi-tool assessment strategy is applied. Qualitative and quantitative analyses must be supported by atmospheric dispersion modelling, odours measurement in the ambient air, participation of population, and control and monitoring activities [1]. Odour impact assessment is composed of the following phases: sampling, characterization, odour emission rates (OER) calculation, atmospheric dispersion modelling, and impact evaluation [2]. The definition of odour emission rates is significantly affected by the sampling conditions and instrumentation. The choice of dispersion model, as well as its parameterization and settings also affect the results. Finally, the interpretation of the results depends on different odour impact criteria, such as the peak-to-mean conversion of concentration values.

Recent research activity brought a significant contribution to the knowledge of odour sampling methods and tools. Odour impact assessment stages are studied worldwide, aiming at standardizing the representativeness of the results [3]. Scholar highlighted that among all impact assessment phases, odour sampling and characterization are the most critical [4].

Following the recommendations brought by the scientific community, institutions of all countries adopted guidelines and regulations to properly address the odour emissions 
problem. Nevertheless, the theme complexity led to different approaches and instruments, resulting in a lack of homogeneity between regulations [5]. Besides, assessment procedures are often incomplete or lack of precise information, generating uncertainties in the results.

The objective of this research work was to evaluate the influence of the variability related to some individual stages of odour impact assessment in the application of the current regulatory criteria. The study focused on the open field correction method for wind velocity used in the calculation of OERs. A WWTP located in Northern Italy, whose odour emissions sources were measured in previous campaigns, was considered as a case study.

Odour dispersion modelling was carried out using the CALPUFF software.

This study was structured by developing a reference impact assessment and simulation according to the Lombardy Region guidelines [6], and subsequently running alternative simulations with a modified OER characterization.

\section{METHODOLOGY}

Odour dispersion of a large WWTP in northern Italy was considered in this study. The approach adopted for the assessment was the one reported in the local regulations of northern Italian regions, that follow international methodologies. In this approach, odour concentrations are evaluated by considering the following odour impact criteria (OIC) [5]: odour concentration thresholds, percentile compliance level, and the averaging time set in dispersion simulations.

This study was elaborated by comparing a reference simulation with other alternative simulations. The reference simulation was conducted according to the guidelines issued by Piedmont Region, Italy. Alternative simulations aimed at evaluating the influence of the open field correction method for wind velocity used in the calculation of OER. These were set up considering the same modelling domain, sources, and odour emission rates, but different alternative correction methods. The most applied relationships were considered, i.e., power law and logarithmic law. Additionally, the application of the D-H correlation was also tested and compared to other solutions.

The power law only depends on the stability class and the prevalent type of land use class of the surface, expressed through the Hellman's unitless $\alpha$ parameter (eqn (1)) [7]:

$$
v_{1}=v_{2} \cdot\left(\frac{h_{1}}{h_{2}}\right)^{\alpha}
$$

where $v_{1}$ is the wind speed at the correct height $\left(\mathrm{m} \mathrm{s}^{-1}\right), v_{2}$ is the wind speed at the meteorological station height $\left(\mathrm{m} \mathrm{s}^{-1}\right), h_{1}$ is the correct height $(\mathrm{m})$, and $h_{2}$ is the meteorological station height $(\mathrm{m})$. The Power Law is considered valid in the $30-300 \mathrm{~m}$ range, although it cannot be applied at the upper and lower limits of the PBL. At heights with values close to the surface roughness length $(1-10 \mathrm{~m})$, it does not provide a valid estimate of the speed. The logarithmic law (eqn (2)) was observed to be more suitable for the evaluation of velocity profiles at a lower height. This relationship accounts for friction velocity $u^{*}$ and surface roughness $z_{0}$. Unlike the power law, it is not an empirical expression as it is derived from the similarity theory, according to eqn (2):

$$
v_{1}=\frac{u^{*}}{K_{v}}\left[\ln \frac{h_{1}}{z_{0}}+\psi\left(\frac{h_{1}}{L_{m}}\right)\right],
$$

where $u^{*}$ is the friction velocity $\left(\mathrm{m} \mathrm{s}^{-1}\right), K_{v}$ is the Von Kármán's constant $(-), z_{0}$ is the surface roughness length $(\mathrm{m}), L_{m}$ is the Monin-Obukhov length $(\mathrm{m})$, and $\psi$ is a stability factor, related to the atmospheric stability class $(-)$. The $\psi$ function is a function of the atmospheric stability [8]. The application of a logarithmic law is often complex because of 
its constituent parameters. In addition to the most used relationships, Lucernoni [8] proposed the application of the Deaves-Harris $(\mathrm{D}-\mathrm{H})$ correlation [7] to odour emissions. The D-H correlation, also known as the logarithmic with parabolic defect model equation, is defined as eqn (3):

$$
v_{1}=\frac{u^{*}}{K_{v}}\left[\ln \frac{h_{1}}{z_{0}}+5.75 \ln \left(\frac{h_{1}}{H}\right)-1.88 \ln \left(\frac{h_{1}}{H}\right)^{2}-1.33 \ln \left(\frac{h_{1}}{H}\right)^{3}+0.25 \ln \left(\frac{h_{1}}{H}\right)^{4}\right],
$$

where, $H$ is the equilibrium boundary layer height, equal to $\frac{u^{*}}{6 f_{c}}(\mathrm{~m}), f_{c}$ is the Coriolis' parameter, equal to $2 \Omega \sin (\varphi)\left(\mathrm{s}^{-1}\right), \Omega$ is the Earth rotation rate, equal to $7.2921 \cdot 10^{-5}$ (rad $\mathrm{s}^{-1}$ ), and $\varphi$ is the latitude ( $\mathrm{rad}$ ). The $\mathrm{D}-\mathrm{H}$ law is an extension of the analysed previous laws since it includes both scale parameters $u^{*}$ and $z_{0}$ (inherited from the logarithmic profile) and the PBL height parameter. This latter depends on wind speed and latitude. In principle, the $\mathrm{D}-\mathrm{H}$ law can accurately describe the entire PBL, including at height values close to upper and lower boundary conditions [7]. However, the applicability of this correlation is complex, since it was calibrated only for a certain range of wind speeds (strong winds of about $20-30 \mathrm{~m} \mathrm{~s}^{-1}$ at $10 \mathrm{~m}$ height above ground). Cook [7] pointed out that in the wind speeds design range the correspondence between $\mathrm{D}-\mathrm{H}$ and power law models is to be considered excellent. For low wind speeds, however, two laws deviate more. More research is still needed to understand which of them provides more realistic profiles in the analysis conditions.

The description of the reference and alternative simulations is reported in Table 1.

Table 1: Alternative simulations for the odour impact assessment of the WWTP case study.

\begin{tabular}{|c|c|}
\hline Simulation & Correction method for wind speed \\
\hline 1 (reference simulation) & Power Law (eqn (1)) \\
\hline 2 & Logarithmic Law (eqn (2)) \\
\hline 3 & Deaves-Harris Law (eqn (3)) \\
\hline
\end{tabular}

\subsection{Study site}

Odour dispersion modelling was applied to a WWTP located in Piedmont Region, Italy. Site orography is mainly flat and presents a slight slope in the south-east direction towards the river in which clarified water is discharged. Some reliefs reaching about $600 \mathrm{~m}$ of elevation above sea level are present in direction SW. The plant is surrounded by two towns, located NW and SE respectively. After the plant construction, urban expansion raised, so that the closest residential area is now located $1 \mathrm{~km}$ to the plant boundary, in direction NW. Except of urban settlements, the area is characterized by mainly agricultural and forest land use.

The two main treatment lines of the WWTP are represented by wastewater treatment and sludge treatment. The water line includes de-gritting facilities (grit and grease removal), primary sedimentation (circular open tanks), anoxic and aeration basins (for organics and nitrogen removal), secondary sedimentation, and final tertiary treatments. The sludge treatment line includes sludge pre-thickening, mesophilic anaerobic digestion, postthickening (centrifuges), and final thermal dewatering.

Sampling and characterization of emission sources were carried out at the plant by mean of several campaigns in 2017 and 2019. This work used olfactometry analysis results to calculate the emission rates, as required by EN13725:2004 standard [9]. In these 
campaigns, air samples from diffused sources were collected employing a wind tunnel (WT). The following facilities were monitored: de-gritting tanks, primary sedimentation tanks, and the external area were treated sludge is temporarily stored). The characteristics of the WT sampling are reported in Table 2. WT sampling flow was $2.5 \mathrm{~m}^{3} / \mathrm{h}$, corresponding to an average velocity of $0.035 \mathrm{~m} / \mathrm{s}$. Odour concentrations were measured by an external laboratory according to standard EN 13725:2004. An ODOURNET TO8 olfactometer and a panel of evaluators was employed with this purpose The results of the olfactometry analysis, expressed in concentration of odour units $\left(\mathrm{OU} \mathrm{m} \mathrm{m}^{-3}\right)$, are reported in Table 3. Odour concentrations were higher in correspondence of de-gritting tanks, primary settlers, and external storage areas for sands and sewage sludge. These concentration values were used to calculate odour emission rates to be introduced into CALPUFF.

Table 2: Characteristics of the WT used for sampling.

\begin{tabular}{|l|l|c|c|}
\hline Parameter & Description & Value & Unit of measure \\
\hline$Q_{\text {effl }}$ & Air flow rate & 2.5 & $\mathrm{~m}^{3} \mathrm{~h}^{-1}$ \\
\hline $\mathrm{T}$ & Temperature & 23 & ${ }^{\circ} \mathrm{C}$ \\
\hline $\mathrm{A}_{\text {base }}$ & WT area & 0.125 & $\mathrm{~m}^{2}$ \\
\hline $\mathrm{U}_{\mathrm{WT}}$ & Sweep air velocity & 0.035 & $\mathrm{~m} \mathrm{~s}^{-1}$ \\
\hline
\end{tabular}

Table 3: Olfactometry analysis results.

\begin{tabular}{|l|c|}
\hline Plant area & Average OU concentration $\left(\mathrm{OU} \mathrm{m}^{-3}\right)$ \\
\hline De-gritting & 180 \\
\hline Primary sedimentation tanks & 540 \\
\hline Stabilized sludge external storage 1 & 1,100 \\
\hline Stabilized sludge external storage 2 & 3,600 \\
\hline
\end{tabular}

In the reference simulation, odour emission rates (OER) were calculated according to the indications provided by the regional technical specifications, starting from the results of the olfactometry analysis. The OER values obtained are reported in Table 4. Each source was introduced in CALPUFF as a stationary source, i.e., OER was assumed to be constant in time.

Table 4: Emission sources characterization.

\begin{tabular}{|l|c|c|}
\hline & Olfactometry results $\left(\mathrm{OU} \mathrm{m}{ }^{-3}\right)$ & OER $\left(\mathrm{OU} \mathrm{s}^{-1}\right)$ \\
\hline De-gritting & 180 & $2,880$. \\
\hline Primary sedimentation tanks & 540 & 12,742 \\
\hline Stabilized sludge external storage 1 & 1,100 & 5,767 \\
\hline Stabilized sludge external storage 2 & 3,600 & 63,360 \\
\hline
\end{tabular}

2.2 The dispersion modelling Odour dispersion modelling and impact assessment

phase was carried out using CALPUFF [10]. CALPUFF is a multi-layer, multi-species, non-steady-state puff dispersion model that simulates the effects of time- and space-varying meteorological conditions on pollution transport, transformation, and removal. The modelling system consists of three main components and a set of pre-processing and postprocessing programs. The main components of the modelling system are CALMET (a 
diagnostic three-dimensional meteorological model), CALPUFF (an air quality dispersion model), and CALPOST (a post-processing package). CALPUFF is a model that simulates puffs of material emitted from modelled sources, reproducing dispersion and transformation processes along the way. Temporal and spatial variations in the meteorological fields selected are explicitly incorporated in the resulting distribution of puffs throughout a simulation period. CALPUFF is widely employed for odour dispersion modelling activities.

Simulations were conducted on grid receptors, in a square domain of $16.2 \times 16.2 \mathrm{~km}$, with 10 vertical layers and a $200 \mathrm{~m}$ grid step. Meteorological data of the year 2018 were collected by a weather monitoring station installed onsite. The weather unit is composed of the following components:

- An ultra-sonic biaxial anemometer, installed at a height of $10 \mathrm{~m}$ above ground;

- A global class 2 radiometer;

- A temperature sensor PT100 1/3 DIN, with a non-vented anti-radiation shield;

- A hygrometer with a non-vented anti-radiation shield;

- A tilt-out tray pluviometer;

- A barometer;

- A Campbell CR800 data logging system.

Odour impact assessment was conducted based on current regulatory indications. Northern Italy technical regulations require the definition of odour concentration maps reporting peak hourly concentrations on an annual basis. The 98th percentile of hourly concentrations must be considered. Odour impact criteria (OIC) require the analysis of three different concentration isophlets:

- $1 \mathrm{OU} \mathrm{m}^{-3}$, corresponding to the $50 \%$ of the population perceiving the smell;

- $3 \mathrm{OU} \mathrm{m}^{-3}$, corresponding to the $85 \%$ of the population perceiving the smell;

- $5 \mathrm{OU} \mathrm{m}^{-3}$, corresponding to the $90-95 \%$ of the population perceiving the smell.

In practical terms, a peak-to-mean factor of 2.3 must be applied to the hourly average odour concentration obtained from dispersion simulations.

\section{RESULTS AND DISCUSSION}

Wind distributions measured by the weather monitoring stations are reported in Fig. 1. This figure shows different wind distributions between night-time and daytime. Night-time is characterized by low wind (around $0.5-1 \mathrm{~m} / \mathrm{s}$ ) with main direction SE. Daytime is characterized by slightly higher wind (up to $5 \mathrm{~m} / \mathrm{s}$ ) with main direction NE. Wind speed is generally low. No significant seasonal variation was evidenced, although higher wind speed is generally observed during spring.

The peak hourly concentrations map of the 98th percentile related to odour dispersion modelling simulations, with reference to Table 1, is reported in Figs 2-4.

Results of Simulation 1 (Fig. 2) showed an extended odour impact area, mainly in the NE-SW direction, consistent with the wind distribution. The $1 \mathrm{OU} \mathrm{m}^{-3}$ isopleth reaches a distance of $6 \mathrm{~km}$ away from the plant boundary. 3 and $5 \mathrm{OU} \mathrm{m}^{-3}$ isopleths, which indicate a greater frequency of nuisance perception by the population, are extended beyond the plant borders and include the nearby residential area. The town located in direction NW is one of the most exposed receptors, together with the national road located north of the plant borders. 


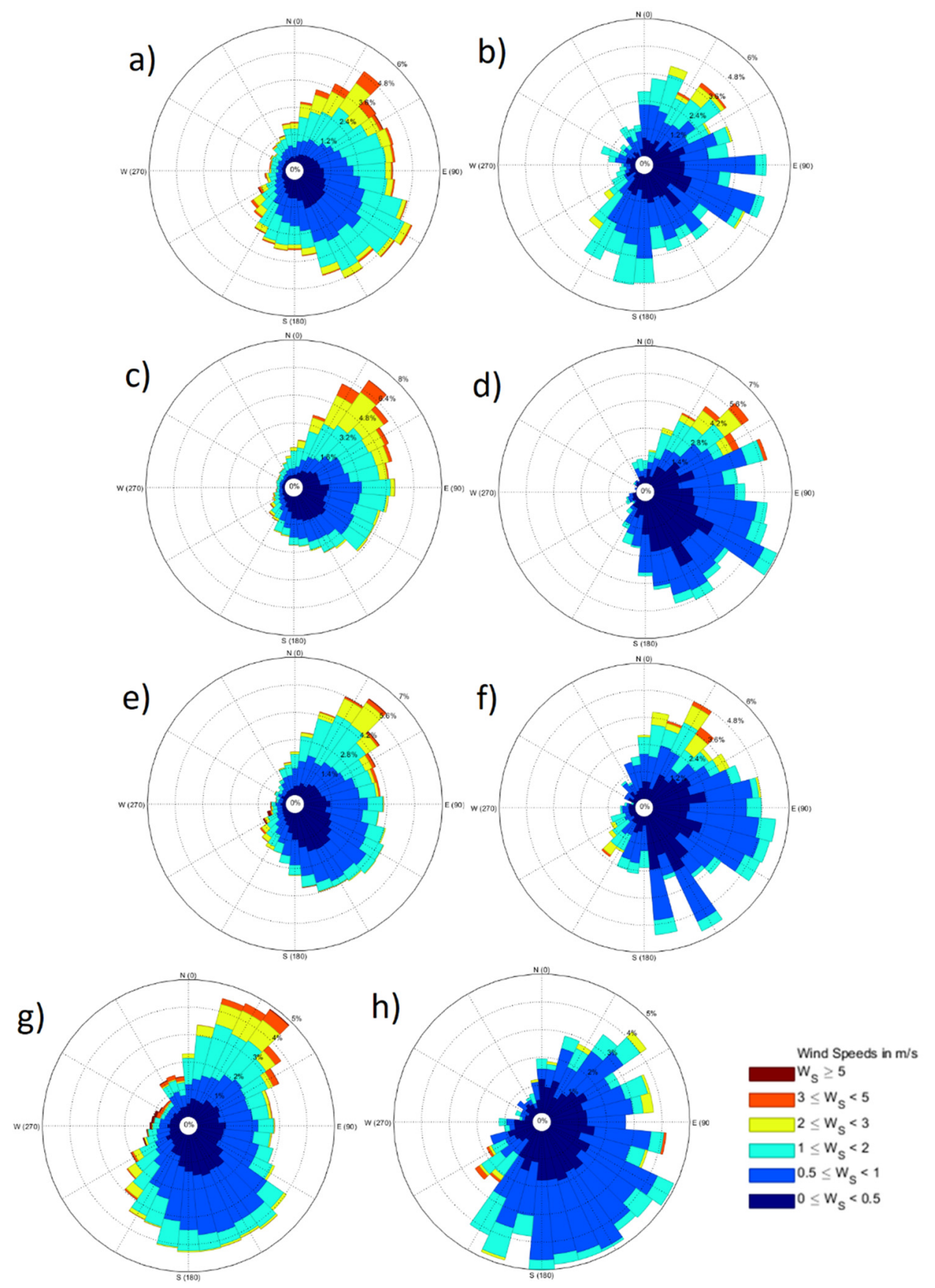

Figure 1: Wind distribution measured onsite. (a) Spring, daytime; (b) Spring, night-time; (c) Summer, daytime; (d) Summer, night-time; (e) Autumn, daytime; (f) Autumn, night-time; (g) Winter, daytime; and (h) Winter, night-time. Daytime distributions represent the average from 8:00 to 19:00. Night-time distributions represent the average from 19:00 to 8:00. 


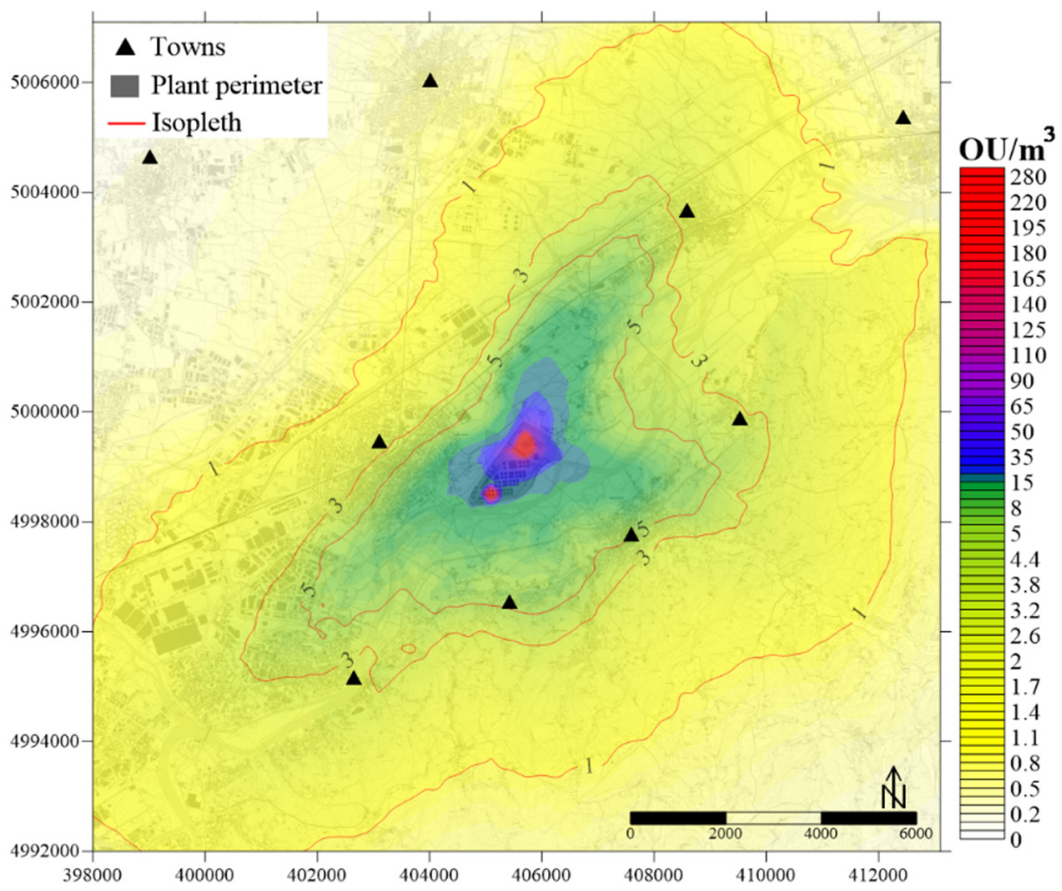

Figure 2: Simulation $1-98$ th percentile peak hourly odour concentration map.

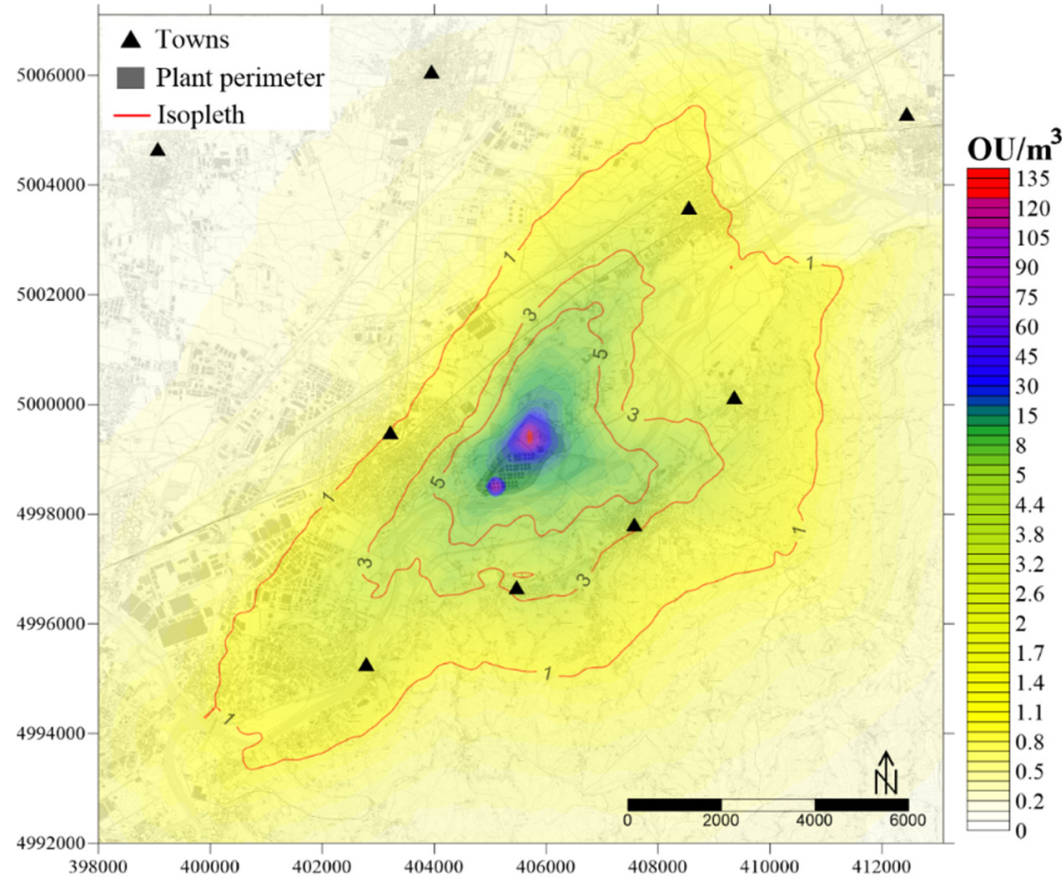

Figure 3: Simulation 2 -98th percentile peak hourly odour concentration map. 


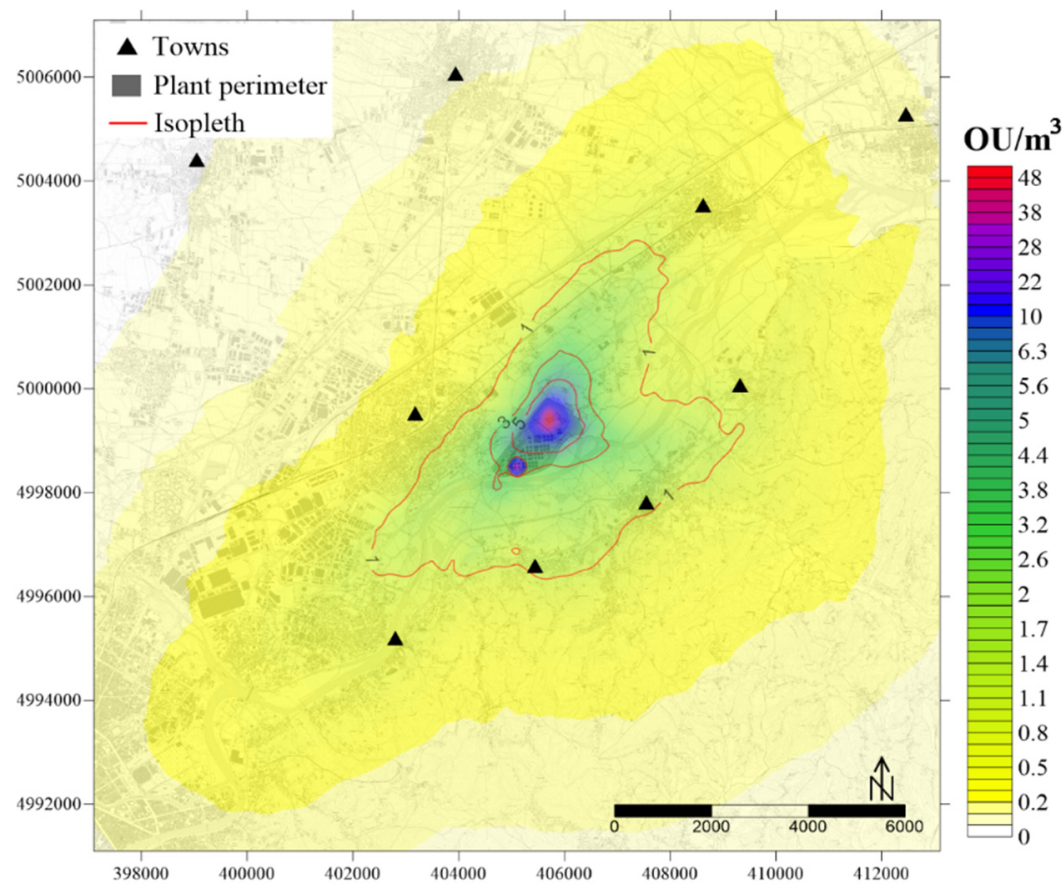

Figure 4: Simulation 3 - 98th percentile peak hourly odour concentration map.

The area underlying the concentration isopleths is the main indicator to investigate the difference between performed simulations. The comparison between impact areas - visible in Fig. 5 shows very pronounced differences between the three adopted laws. The impact area varies depending on the selected method. Taking the power law as the reference, the average variability of the impact areas was between $-33 \%$ and $-48 \%$ if the logarithmic law was applied, and $-83 \%$ and $-94 \%$ if the D-H law was applied.

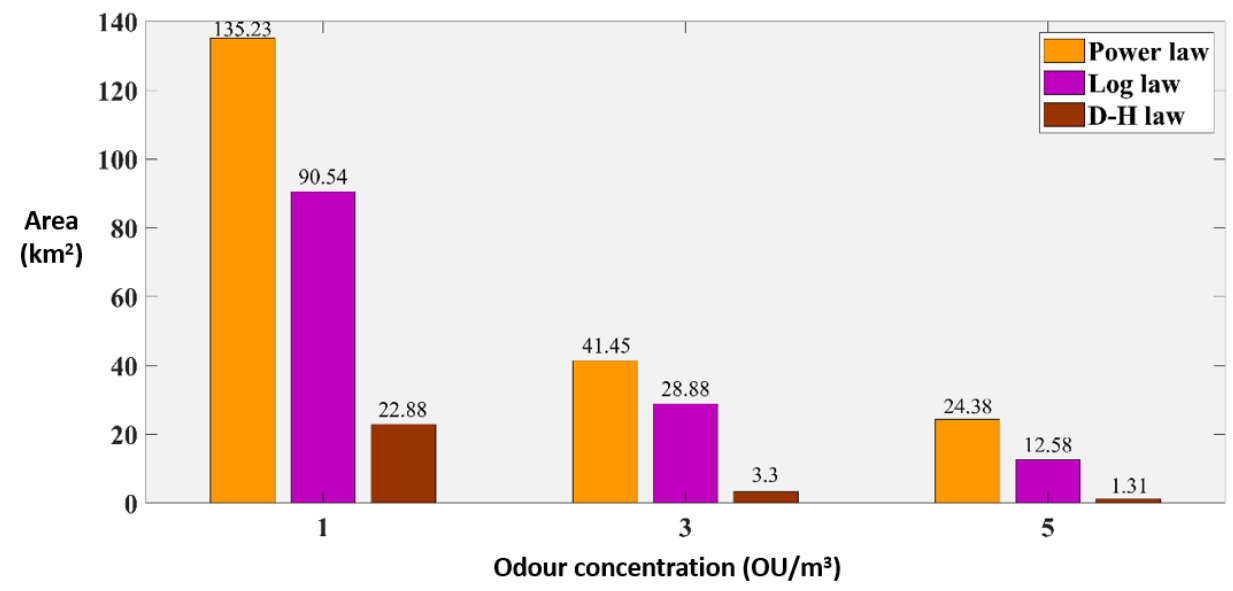

Figure 5: Simulations 1, 2, and 3 - Comparison between 1, 3, and $5 \mathrm{OU} \mathrm{m}^{-3}$ isopleths. 
Simulations results showed large impact extension in the study domain. No odour field measurements were conducted in support of these results. However, it is likely that the OIC applied lead to an overestimation of the impact area. With regard to Simulation 1, the area covered by the $1 \mathrm{OU} / \mathrm{m}^{3}$ isopleth reached an extension larger than the town surrounding the plant (Fig. 2). This would mean that $50 \%$ of the population living in that area would perceive the smell for $98 \%$ of the year. Such a situation is not evidenced by the information available, neither by reports from the monitoring agency, nor by surveys from living population. Such an overestimation of impacts connected to the application of OIC in northern Italian regions was already observed by other studies.

Besides this consideration, the results showed very pronounced differences (up to $94 \%$ in terms of impact area) between the three adopted laws. The adoption of the logarithmic law, which more accurately describes the speed profile for height close to $z_{0}$, corresponds to a significant reduction of the impact area. The application of the $\mathrm{D}-\mathrm{H}$ law corresponds to a further reduction. There is not enough data available to define which simulation is the more realistic. The results obtained should be compared with field measurements, although the extensive application of dynamic olfactometry is cost and time expensive. Thus, from the results, it is not possible to define if a simulation is better than another. However, considered the general absence of complaints about odour nuisance by the living population, impact areas of Simulation 3 seem actually more realistic. Considering its theoretical formulation, the application of the $\mathrm{D}-\mathrm{H}$ law can be considered interesting. This relationship describes the whole PBL, as it derives from combining a logarithmic function with a 4th order polynomial [11]. Nevertheless, its applicability must be deepened by future studies.

Uncertainty related to regulatory odour impact assessment is a debated topic. Since regulations provide no information about the methodology to be adopted, this study demonstrated how the selection of one or another solution could generate significant variability in the results. Most of the research work is currently done on finding the most effective correlation between emissive flows in the open field and within the dynamic hoods. Regarding the OER calculation methodology, there is still the need of efforts to reach an agreement on the law used to describe the wind speed profile. Lucernoni [8] studied the influence on the velocity law by comparing the same three relationship considered in this study. The results showed a variability of separation distances that is consistent with the results of this study. The same authors also highlighted that the logarithmic profile is more reliable at reduced heights from the ground $(0-100 \mathrm{~m})$. The same authors, in a subsequent literature work about the OER correction, also highlighted the possibility of adopting the D-H relationship [12].

\section{CONCLUSIONS}

The objective of the present study was to investigate the variability of emission rate definition in regulatory odour impact assessment. Odour dispersion modelling was applied to a case study - a wastewater treatment plant located in northern Italy. The representativeness of the analysis depends on the application of current regulatory provisions on odour emissions, which presently require more detailed and standardized methodologies. In this context, this study showed that a single phase of the analysis can bring inherent uncertainty in the overall procedure, as impact areas can vary up to $94 \%$ depending on the evaluator's choices. Existing regulatory tools must be checked and reviewed based on this and other studies.

The analysis of odour dispersion modelling showed a WWTP odorous impact on the study area that is probably overestimated, as no evidence is present when considering 
conditions of the population living in this area. Nor previous inspection and monitoring activities evidenced such olfactory nuisance. The adoption of the power law profile may have contributed to this overestimation: this is the simplest correlation and its representativeness is lower at low heights from the ground. The logarithmic law can be considered more representative, both from the literature studies analysed and based on the results of the analysis. The third proposed correlation, the Deaves-Harris law, is interesting but needs further analyses, as it still need a more detailed validation for this kind of applications. Impact maps need to be compared with the field reports results and a future survey on the population, including citizen science initiatives. Such an approach would lead to a better understanding of the relationships between model results and the actual perceived olfactory nuisance. Further studies are needed to optimize the evaluation method and the comparison between dispersion models results and odour impact criteria. This would allow institutions to translate the method into uniform regulatory references at the national level, limiting results variability and improving their representativeness.

\section{REFERENCES}

[1] Byliński, H., Kolasińska, P., Dymerski, T., Gębicki, J. \& Namieśnik, J., Determination of odour concentration by TD-GC $\times$ GC-TOF-MS and field olfactometry techniques. Monatshefte für Chemie, 148, pp. 1651-1659, 2017. DOI: $10.1007 / \mathrm{s} 00706-017-2023-8$.

[2] Belgiorno, V., Naddeo, V. \& Zarra, T., Odour Impact Assessment Handbook. John Wiley \& Sons, 2013.

[3] Ravina, M. et al., Integrated model for estimating odor emissions from civil wastewater treatment plants. Environmental Science and Pollution Research, 27, pp. 3992-4007, 2020. DOI: 10.1007/s11356-019-06939-5.

[4] Ravina, M. et al., Characterization of odorous emissions from a civil wastewater treatment plant in Italy, Aveiro, Portugal, pp. 159-170, 2019.

[5] Brancher, M., Griffiths, K., Franco, D. \& Lisboa, H., A review of odour impact criteria in selected countries around the world. Chemosphere, 168, pp. 1531-1570, 2017. DOI: 10.1016/j.chemosphere.2016.11.160.

[6] Invernizzi, M., Bellini, A., Miola, R., Capelli, L., Busini, V. \& Sironi, S., Assessment of the chemical-physical variables affecting the evaporation of organic compounds from aqueous solutions in a sampling wind tunnel. Chemosphere, 220, pp. 353-361, 2019. DOI: 10.1016/j.chemosphere.2018.12.124.

[7] Cook, N.J., The Deaves and Harris ABL model applied to heterogeneous terrain. Journal of Wind Engineering and Industrial Aerodynamics, 66(3), pp. 197-214, 1997. DOI: 10.1016/S0167-6105(97)00034-2.

[8] Lucernoni, F., The evaluation of the odour emission rate for passive area sources: A new approach. Chemical Engineering Transactions, 43, 2015.

[9] EN 13725:2004, Air quality: Determination of odour concentration by dynamic olfactometry.

[10] Scire, J., Robe, F., Fernau, M. \& Yamartino, R., A user's guide for the CALMET meteorological model (Version 5), 1998.

[11] Scire, J., Strimaitis, D. \& Yamartino, R., A user's guide for the CALPUFF dispersion model. Earth Tech, Inc., p. 521, 2000.

[12] Lucernoni, F., Capelli, L., Busini, V. \& Sironi, S., A model to relate wind tunnel measurements to open field odorant emissions from liquid area sources. Atmospheric Environment, 157, pp. 10-17, 2017. DOI: 10.1016/j.biortech.2007.04.034. 